\title{
Occupational IgE sensitisation to phytase, a phosphatase derived from Aspergillus niger
}

\author{
Gert Doekes, Nelleke Kamminga, Loes Helwegen, Dick Heederik
}

\begin{abstract}
Objective-Phytase is a phosphatase derived from Aspergillus niger that enhances phosphate bioavailability in the gut, and therefore has been increasingly used as an animal feed additive since the early 1990s. The aim of this study was to assess whether work related respiratory symptoms among workers in a so called premix factory producing animal feed additives, could be due to type I (mediated by immunoglobulin E (IgE)) allergic sensitisation to phytase.
\end{abstract}

Methods-Preparations of specific IgE against phytase as used in the factory were assessed by enzyme immunoassay (EIA) in serum samples of 11 exposed workers who regularly handled the enzyme, in 11 office and laboratory workers of the same plant (non-exposed internal controls), and in 19 laboratory animal workers as external controls. The factory workers also completed a questionnaire on common and work related respiratory symptoms.

Results-Depending on the cut off level in the EIA for IgE, and the preparation used as coated allergen, antiphytase sensitisation was found in one to four of the 19 external controls, in one to five of the 11 internal controls, and in four to 10 of the 11 exposed workers. Strongest IgE reactions were found in four exposed workers who reported work related respiratory symptoms, particularly wheezing, and in one internal control who possibly had become sensitised because the structure of the factory building did not preclude airborne exposure in the offices and corridors of the plant. Experiments with inhibition EIA for IgE showed that $(a)$ phytase of another commercial source was only partially cross reactive with phytase as used in the premix factory, and (b) phytase used as an animal feed additive did not cross react with common mould extracts, except for extracts from the species of origin, Aspergillus niger. The amount of IgE binding phytase in $A s$ pergillus niger was estimated to be between $0.1 \%$ and $1 \%$ of the extractable mould proteins.

Conclusions-Phytase is a potentially important new occupational allergen causing specific IgE immune responses among exposed workers. Such IgE sensitisation could probably be the cause of work related asthmatic and other respiratory symptoms if no effective measures are taken to prevent airborne occupational exposure at sites where phytase is handled, particularly during addition of enzyme preparations to animal feed.

(Occup Environ Med 1999;56:454-459)

Keywords: enzyme allergy; IgE; phytase; Aspergillus niger; animal feed

Advances in biotechnology during the past decades have led to a remarkable increase in the use of industrial enzymes, usually of microbial origin. New enzymes have been introduced to the feed and food industry, in household products such as washing powders, and in various other applications. ${ }^{1}$ Large scale production of various new enzymes has become possiblefor example, by using genetically modified strains of micro-organisms that can be easily cultured under well controlled conditions. Modification may involve duplication of genes of interest, stimulation of gene expression by modifying promotor regions in the DNA, or incorporation into the genome enzyme coding genes from other species that are more difficult to culture. As many industrial enzymes are known as type I allergens, ${ }^{2-5}$ the appearance of these new enzymes on the market probably implicates a simultaneous increase in exposure to allergens, particularly in occupational populations involved in enzyme production and delivery, and in industries where new enzyme preparations are applied.

Phytase has been introduced in the early 90s in the animal feed industry. Phytase is a phosphatase that releases phosphate from phosphorylated carbohydrate-particularly from the indigestible phytate or phytinic acid-thus enhancing the bioavailability of phosphate in the gut of the animals, ${ }^{6-8}$ and reducing the need for phosphate supplements in the feed. In this way phosphate concentrations in the manure and emissions of phosphate into the environment could be reduced considerably. The currently used phytase preparations, produced from genetically modified strains of Aspergillus niger (variety ficuum), are highly effective, and reduction of environmental emissions of phosphate by up to $30 \%$ or more has been reported. ${ }^{8}{ }^{9}$ It is thus not surprising that the use of phytase as animal feed additive has found wide acceptance and application.

Up to now, no allergic or other adverse reactions to phytase have been published. In this report we describe a serological and health survey in a factory producing premixesspecialised products containing vitamins, antibiotics, and other additives including phytase, for use in animal feed production. The study 
was performed because some workers in this factory reported serious work related respiratory health problems, particularly during and after handling phytase preparations.

\section{Materials and methods}

POPULATION AND WORKPLACE

The study was inititated in the summer of 1995 , because of a case of presumably work related respiratory illness in the premix factory. The worker reported respiratory symptomsparticularly wheezing and shortness of breathduring addition of phytase to batches of animal feed, one of his regular jobs. Two formulations of phytase from the same supplier were used: a solid powder and a concentrated phytase solution (both with tradename Natuphos, Gistbrocades, Delft, The Netherlands). During the production process the enzyme powder was added usually simply by hand, and the liquid preparation was sprayed as an aerosol.

A small occupational health survey in the factory was performed. From the 60 workers in the production hall, 11 exposed workersthose who regularly worked with phytase or at a site close to where phytase was handledwere asked to participate. As an internal control group, 11 non-exposed subjects were selected who worked in the office $(n=8)$, the laboratory $(n=2)$, or the restaurant $(n=1)$ of the same factory. The survey included a standardised respiratory health questionnaire as used in previous studies, ${ }^{10} 11$ and serology to detect specific IgE sensitisation to phytase, and to assess the presence of atopy as a probable risk factor or effect modifier. In IgE serology we also included an external control group of 19 serum samples from laboratory animal workers. ${ }^{10}$ Of these 19 donors, 14 were atopic as defined by a positive IgE serology on a panel of four common allergens, or an enhanced $(>100 \mathrm{kU} / \mathrm{l})$ total serum IgE. ${ }^{12}$

As workers in the animal feed industry have an increased risk of respiratory disorders or impaired lung function due to exposure to organic dust, and particularly endotoxins, ${ }^{13} 14$ we also included a limited series of personal and ambient air samples to assess dust and endotoxin concentrations in this particular factory.

DUST AND ENDOTOXIN EXPOSURE

Personal full shift air sampling was performed as described earlier, with Gilair samplers and PAS-6 sampling heads equipped with glass fibre filters (GF/A $2.5 \mathrm{~cm}$; Whatman International, UK); air was sampled at $2 \mathrm{l} / \mathrm{min} .{ }^{15} \mathrm{In}$ total 24 samples were taken for gravimetric assessment of dust concentrations. In 13 of these samples endotoxin was also measured. Filters were extracted with $5 \mathrm{ml}$ pyrogen free water with $0.05 \%$ Tween-20, and endotoxin was measured in the extracts with a kinetic limulus amoebocyte lysate (LAL) assay as described earlier. ${ }^{16}$ Concentrations were expressed in endotoxin units $(\mathrm{EU}) / \mathrm{ml}$ or $/ \mathrm{m}^{3}$, in which $110 \mathrm{EU}$ corresponds to about $1 \mathrm{ng}$.
ENZYME AND ALLERGEN PREPARATIONS Allergen preparations were obtained by extraction and dialysis of the solid and the liquid phytase preparations used in the factory. Solid phytase $(2.5 \mathrm{~g})$ was extracted for 2 days at $8^{\circ} \mathrm{C}$ with $20 \mathrm{ml}$ Coca's buffer $(0.94 \mathrm{M} \mathrm{NaCl}, 0.03$ $\mathrm{M} \mathrm{NaHCO}_{3}$, phenol $0.04 \mathrm{M}$, pH 7.2). After centrifugation for 30 minutes at $24500 \mathrm{~g}$, the supernatant was filtered through $0.45 \mu \mathrm{m}$ filters (Millipore, Molsheim, France), and then extensively dialysed against phosphate buffered saline (PBS). The liquid phytase preparation $(20 \mathrm{ml})$ was centrifuged, filtered and dialysed against PBS, as described for the extract of the solid product. Protein (BCA method, Pierce, Rockford, IL, USA ${ }^{17}$ ) and carbohydrate ${ }^{18}$ were measured as indicated. The powder extract (labelled as phytase-Ns) contained $8 \mathrm{mg} / \mathrm{ml}$ protein and $1 \mathrm{mg} / \mathrm{ml}$ carbohydrate, and the processed liquid preparation (phytase-Nf) contained $28 \mathrm{mg} / \mathrm{ml}$ protein and $4 \mathrm{mg} / \mathrm{ml}$ carbohydrate.

Commercially available lyophilised phytase from Aspergillus niger was purchased from Sigma Chemicals (St Louis, MO, USA; product No P 9792); the $1 \mathrm{mg} / \mathrm{ml}$ solution in PBS consisted of nearly $100 \%$ protein. This preparation was labelled phytase-S.

Common allergen extracts from house dust mites, grass, tree pollen, pets, and extracts of fungal species Aspergillus niger, Aspergillus oryzae, Aspergillus flavus, Aspergillus fumigatus, and a mix of Penicillium species (Penicillium-4) were obtained from ALK Benelux (Houten, The Netherlands); $\alpha$-amylase from Aspergillus oryzae, used previously in studies on baker's allergy, ${ }^{11}$ came from NOVO Nordisk (Fungamyl 1600S; NOVO Nordisk, Bagsvaerd, Denmark).

\section{IgE SEROLOGY}

Specific IgE antibodies reacting with phytase allergen preparations, with mould extracts, or with the common allergens were measured by IgE enzyme immunoassay (EIA). ${ }^{12}$ The various phytase preparations were coated to microwells at 1:100 dilution in PBS, whereas the mould extracts and other common allergens were coated at $10-25 \mu \mathrm{g} / \mathrm{ml}$. Diluted serum was incubated in coated microwells in PBS with $0.05 \%$ Tween-20 and $0.2 \%$ gelatin, and bound IgE was measured by sequential incubation with mouse monoclonal antihuman IgE, affinity purified and biotinylated rabbit antimouse $\mathrm{Ig}$, and avidin peroxidase, all in PBS-Tweengelatin, after which $o$-phenylenediamine was used as the peroxidase substrate. After addition of $2 \mathrm{~N} \mathrm{HCl}$, the optical density was read at 492 $\mathrm{nm}$.

Total IgE was determined by a sandwich EIA method. $^{12}$

INHIBITION IgE ENZYME IMMUNOASSAY

Cross reactivity of allergen preparations was tested by IgE inhibition EIA essentially as described earlier. ${ }^{19}$ Aliquots of $50 \mu \mathrm{l}$ test samples were added to coated wells, after which $50 \mu \mathrm{l}$ of a diluted positive serum were added to each well and mixed. The assay was further continued as is standard procedure for 
the specific IgE EIA. The dilution of the positive serum samples was at least $1 / 5$, and such that the optical density at $492 \mathrm{~nm}\left(\mathrm{OD}_{492}\right)$ for the no inhibitor controls - diluted serum mixed with PBS-Tween-gelatin-was between 1.0 and 2.0 .

\section{Results}

Dust and endotoxin exposures were similar to those found in previous studies in the animal feed industry. ${ }^{13}$ Although some protective measures were taken against exposure to dust - such as the use of a hood-there was visible exposure in the breathing zone during enzyme application. Geometric mean dust concentrations for 8 hour averaged exposure in various job titles or tasks ranged from 1.8 to $10.5 \mathrm{mg} / \mathrm{m}^{3}$; minimum and maximum values in any of the measurements were 0.9 and 56.0 $\mathrm{mg} / \mathrm{m}^{3}$. Endotoxin exposures assessed by area sampling ranged from about 16 to $>1000$ $\mathrm{EU} / \mathrm{m}^{3}$. Although the small numbers per sampling site precluded definite conclusions, endotoxin exposure seemed to be higher (up to $950 \mathrm{EU} / \mathrm{m}^{3}$ ) at sites where the enzyme phytase was handled (not shown).

Figure 1 summarises the $\operatorname{IgE}$ reactions of serum samples of workers and controls with phytase-Nf. In the external control group one weakly positive reaction and two borderline reactions (OD between 0.05 and 0.10 above the OD of the no serum control) were noted, whereas of the 11 internal controls one reacted strongly, and two showed a borderline $\operatorname{IgE}$ reaction. By contrast, four of the 11 exposed production workers reacted definitely and four had a borderline reaction. The IgE reactions with phytase-Nf in the exposed group were significantly stronger than in either the external or the internal controls (both $\mathrm{p}<0.005$; MannWhitney rank sum test). The assay with phytase-Ns seemed to be more sensitive, but the $\operatorname{IgE}$ reactions with the two preparations were highly correlated, with an $r^{2}$ for log transformed OD values of $>0.95$ (not shown). Thus, positive (OD > OD(blank)+0.100) and borderline (0.05- 0.10 above the OD(blank)) reactions on phytase-Ns were found in two and

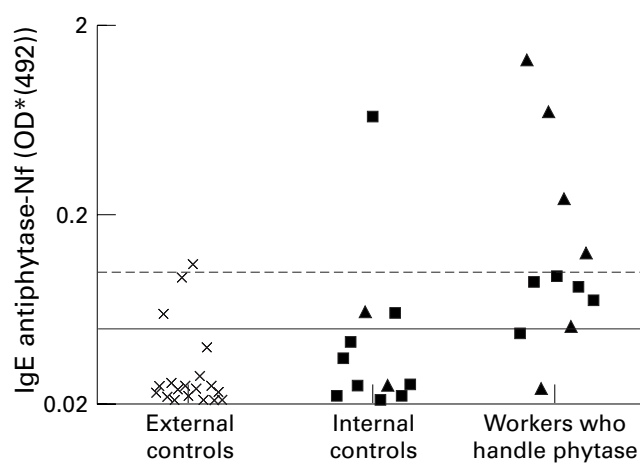

Figure 1 IgE antiphytase-Nf in external controls, in internal controls, and in workers who regularly handled phytase. Triangles and squares indicate serum samples from workers with or without work related respiratory symptoms, respectively. $O D^{*}$ (492) represents the $\mathrm{OD}_{492}$ in EIA wells with test serum at $1 / 10$, minus the mean $\mathrm{OD}_{492}$ in wells with only diluent instead of serum. Horizontal lines indicate the lower (0.05) and higher (0.10) threshold values for a positive reaction. two of the 19 external controls, in three and two of the 11 internal controls, and in nine and one of the 11 exposed workers, respectively. Also the IgE reactivity with phytase-Ns was significantly higher in exposed workers than in external or internal controls $(\mathrm{p}<0.005$; MannWhitney rank sum test).

Six of the 11 exposed workers reported work related respiratory symptoms: four reported wheezing, chest tightness or shortness of breath, one worker only cough, and one both cough and asthmatic symptoms. As shown by the different symbols (fig 1), most of these symptomatic workers were sensitised to phytase, and the four workers with the highest IgE titres all reported symptoms. By contrast, only two workers in the non-exposed group reported work related respiratory symptoms: one worker who was (weakly) sensitised had both asthmatic complaints and cough, and another who was not phytase-sensitised reported wheezing. The office worker with the strong IgE antiphytase reaction reported respiratory symptoms when at home after work, but did not clearly identify the complaints as work related, and was therefore labelled as having no work related respiratory symptoms.

Three workers in the internal control group and four in the exposed group were atopic, as determined by EIA for total and allergen specific IgE. ${ }^{12}$ There was a tendency to more and stronger IgE antiphytase reactions among the atopic people, but certainly no perfect association (not shown). In fact, one worker in the exposed group with moderate sensitisation and complaints, and the office worker with the strong antiphytase reaction, had no $\operatorname{IgE}$ to common allergens or enhanced total IgE. The other non-atopic workers all showed only weak or no IgE reactions to phytase.

When tested in microwells coated with phytase from a different source (phytase-S), only one serum sample showed a positive IgE reaction, from one of the internal controls who had a weak positive reaction towards phytase-Ns and phytase-Nf, whereas all serum samples with high IgE antiphytase-Ns and antiphytase-Nf were negative on phytase-S. Inhibition EIA experiments however showed that phytase-S did contain the IgE-binding components of phytase-Ns/Nf, but at much lower concentrations (fig 2): complete inhibition could be achieved, but at about 20-50 times higher concentrations.

To investigate cross reactivity with common mould allergens, all serum samples from the 11 internal controls and the 11 exposed workers were also tested for IgE against extracts of three Aspergillus species-Aspergillus fumigatus, Aspergillus oryzae, and Aspergillus niger-and a mix of four Penicillium species. No positive IgE reactions were found with Aspergillus fumigatus, Aspergillus oryzae, or Penicillium species, whereas two serum samples had detectable IgE against Aspergillus niger: the serum from the office worker with strong phytase sensitisation, and one of the two serum samples from exposed workers with strong $\operatorname{IgE}$ antiphytase sensitisation. These reactions with Aspergillus niger were most likely due to cross reactivity, as 

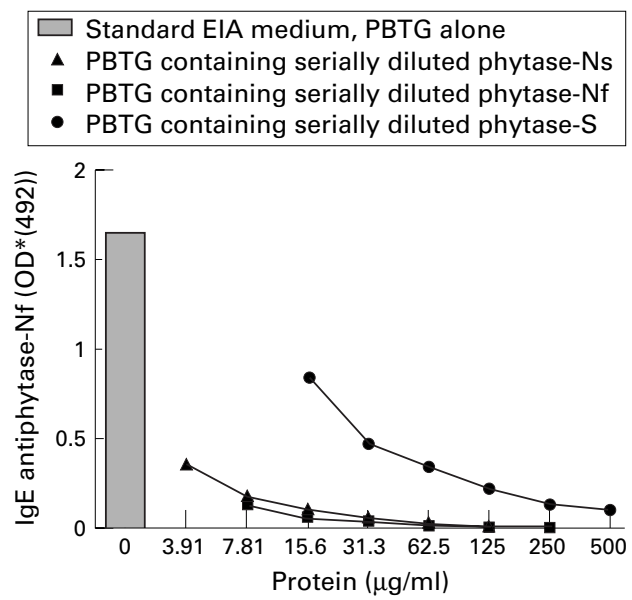

Figure 2 Allergenic cross reactivity of phytase preparations, as shown by inhibition of the $\operatorname{IgE}$ reaction with a coating of phytase-Nf. One of the serum samples from exposed workers with a strong IgE antiphytase reaction was tested in the EIA at 1/10.

the Aspergillus niger preparation, but not the other mould extracts, could inhibit the reactions of these serum samples with coated phytase-Ns and -Nf. The inhibition curves (fig $3 \mathrm{~A}, \mathrm{~B}$ ) indicated that between $0.05 \%$ and $1 \%$ of the crude Aspergillus niger extract would be allergenic phytase.
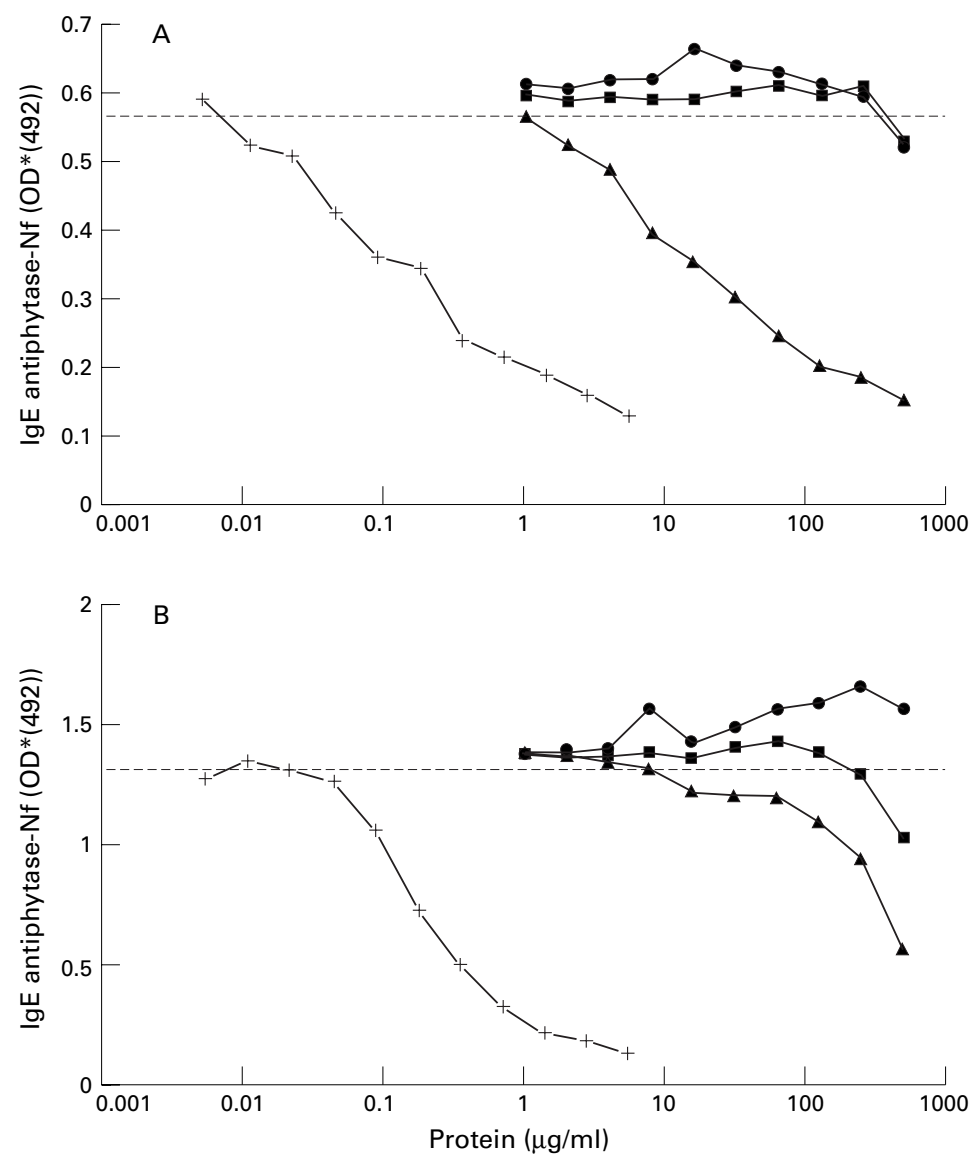

Figure 3 Inhibition of $\operatorname{IgE}$ antiphytase- $N f(A)$ of one exposed worker and $(B)$ from one internal control, by serially diluted phytase-Nf $(+)$, and extracts of Aspergillus niger (triangles), Aspergillus fumigatus (squares), and Aspergillus oryzae (closed circles). The broken line indicates the (corrected) $O D_{492}$ values in wells with only diluted serum and no inhibitor.

\section{Discussion}

Phytase has been introduced as an animal feed additive in the early 1990s, and has since then found wide application; to our knowledge without any report of adverse health effects. This report would thus be the first in which occupational IgE sensitisation to phytase is described, although recently antiphytase sensitisation has also been found in enzyme production in Germany (personal communication, Baur et al, Bochum, Germany). The apparent association with work related respiratory symptoms (fig 1) suggests that $\operatorname{IgE}$ sensitisation to phytase was indeed also the cause of asthmatic symptoms in the proband as well as in the other workers. Obviously, confirmation of this conclusion would require further examinations of exposed, sensitised, or symptomatic workersfor example, by allergen specific provocation or by peak flow monitoring before, during, and after the work shift. Nevertheless, the high prevalence of phytase specific sensitisation indicates that phytase must be considered, like other industrial enzymes, as an occupational allergen, and should be handled as such in the work environment. In fact, the supplier provides a printed warning that in principle phytase may be a sensitiser, and within the studied premix factory a hood was used at the site of enzyme application. This, however, seemed to be insufficient to prevent sensitisation in this particular facility, and the present findings thus clearly confirm that manual handling of enzyme powders or spraying of enzyme solutions at the workplace implicate a high risk of occupational allergic sensitisation.

The positive reactions in the two control groups might raise questions about the specificity of the antiphytase IgE assay. However, the strongest sensitisation was clearly found in workers who were regularly involved in enzyme application, and among laboratory animal workers only weak or marginally positive reactions were noted (fig 1). At first sight more surprising was the strong reaction in one of the office workers. A possible explanation may be found in the structure of the building, in which the office rooms were situated close to, and in direct connection with the production hall when the door was opened. Thus the risk of exposure was certainly not zero for office workers, especially not when leaving their room and going through the factory.

Actual exposure measurements would be required to verify that assumption, but an assay for airborne phytase concentrations is not available as yet. We eluted soluble material from the filters collected during dust sampling in the present study and tried to measure phytase in the extracts, with an $\mathrm{IgG}_{4}$ inhibition assay as in our previous studies on exposure to wheat and potato antigen, ${ }^{20}{ }^{21}$ but no phytase anti-allergen could be detected. This might have been due to non-optimal extraction conditions and media, as data from our own and other laboratories indicate that for several allergens the addition of a mild detergent such as Tween-20 markedly increases the yield of eluted allergens. ${ }^{22}{ }^{23} \mathrm{~A}$ more likely explanation may be the relatively low sensitivity of the $\mathrm{IgG}_{4}$ inhibition assay, which was 
in the same order of magnitude as for IgE inhibition (fig 3), and comparable with the sensitivity of the inhibition EIAs for potato or wheat proteins (with a detection limit of about 10-25 $\mathrm{ng} / \mathrm{ml}) .^{20}{ }^{21}$ Thus, detection limits for airborne phytase would be at least $25-50 \mathrm{ng} / \mathrm{m}^{3}$, which in fact is a high concentration for a single protein allergen. For instance, we previously defined high exposure to fungal $\alpha$-amylase in bakeries as job titles with a geometric mean exposure of only $18 \mathrm{ng} / \mathrm{m}^{3}$, and a significantly enhanced risk of occupational sensitisation and symptomatic airway disease was found at this exposure, but also at much lower mean $\alpha$-amylase concentrations of only 1-2 $\mathrm{ng} / \mathrm{m}^{3} .{ }^{11}$ Thus a much more sensitive assay would also be required for assessment of exposure to airborne phytase, presumably a sandwich immunoassay with monoclonal or polyclonal antibodies from animals specifically immunised with purified phytase.

The prevalence of reported work related respiratory symptoms was remarkably high in this small sample: especially wheezing and shortness of breath were reported by five of the 11 exposed workers, and by only two of the 11 office workers. Part of these symptoms might have been due to exposure to dust or endotoxin which seemed to be of the same order of magnitude as concentrations at which respiratory health effects have been found in the animal feed industry. ${ }^{1314}$ On the other hand, among the exposed workers the strongest IgE antiphytase sensitisation was found among workers with work related symptoms, and it therefore seems highly likely that the $\operatorname{IgE}$ immune response to phytase, like sensitisation to other enzymes, can be an important aetiological factor in the development of work related respiratory disease.

Commercially available enzyme preparations are usually not purified to complete homogeneity, and allergic sensitisation may thus often be directed to either the active enzyme itself or to one or more of the impurities. This may explain why there was only partial cross reactivity with Aspergillus niger phytase from another source (fig 3). In preliminary blotting experiments we found staining patterns that were nearly identical for phytase-Ns and phytase-Nf, but different for phytase-S (not shown). If these findings can be confirmed and it could be shown that IgE sensitisation in some people is mainly directed at impurities, production of phytase preparations with similarly high enzymatic activity, but with lower allergenic potency should in principle be possible.

The lack of cross reactivity with phytase-S may also be due to the use of a recombinant Aspergillus niger strain for the production of phytase-Ns and -Nf. It might be speculated that the gene product of these genetically modified microorganisms differs in its fine structure from the enzyme produced by the native gene, such that a different set of epitopes is expressed on the recombinant phytase. This also would require a much more detailed immunochemical analysis of the epitopes binding the antiphytase $\operatorname{IgE}$ antibodies. If so, it might be speculated whether modern biotechnological techniques are capable of producing recombinant enzymes, in which the active or otherwise functionally important sites are fully expressed but from which allergenic epitopes have been removed.

The IgE inhibition assay with common mould extracts (fig 3) indicated that allergenic (or better: IgE binding) phytase would be present in Aspergillus niger, but not in other extracts. This implies that in principle sensitisation to Aspergillus niger phytase may occur as a consequence of exposure to Aspergillus niger in the general (indoor home) environment. The only two positive IgE antimould reactions found in our population were, however, directed to Aspergillus niger, and not to the other common moulds, and these two serum samples both reacted strongly with isolated phytase. Therefore these IgE reactions against Aspergillus niger were probably the consequence, and not the cause of phytase sensitisation, which thus really would be work related. We therefore conclude that the present study has identified a new example of occupational enzyme allergy, and that strict control measures at the workplace are required to keep airborne exposure low and to ensure that the risk of sensitisation and work related respiratory disease will be minimal.

The study was financially supported by the premix factory. We thank staff and personnel for their cooperation and willingness to provide blood samples for serology. Leo Elders, occupational physician, is acknowledged for cooperation and advice. The technical assistance of Siegfried de Wind and Jack Spithoven in producing phytase preparations and setting up the EIA for antiphytase IgE, is greatly appreciated.

1 Brisman J. The Nordic Expert Group for Criteria Documentation of Health Risks from Chemicals. 111. Industrial enzymes. Solna, Sweden: Arbetsmiljoeinstitutet (Natl Inst for the Working Life), 1994:28.

2 Flindt MLH. Pulmonary disease due to inhalation of derivates of Bacillus subtilis: containing proteolytic enzyme. Lancet 1969;i:1177-84.

3 Pauwels R, Devos M, Callen L, et al. Respiratory hazard from proteolytic enzymes. Lancet 1978;ii: 1669.

4 Flindt MLH. Biological miracles and misadventures: identification of sensitisation and asthma in enzyme dertergent workers. Am F Ind Med 1996;29:99-110.

5 Johnson CR, Soerensen TB, Larsen AI, et al. Allergy risk in an enzyme producing plant: a retrospective follow up study. Occup Environ Med 1997;54:671-5.

6 Simons PCM, Versteegh HAJ, Jongbloed AW, et al. Improvement of phosphorus availability by microbial phytase in broilers and pigs. Brf Nutr 1990;64:525-40.

7 Nasi M. Microbial phytase supplementation for improving availability of plant phosphorus in the diet of the growing pigs. Fournal of the Agricultural Society of Finland 1990;62: 435-43.

8 Kemme PA. Phytate and phytases in pig nutrition [thesis]. Utrecht, The Netherlands: University of Utrecht, 1998.

9 Selten G. The versatile Aspergillus niger. The Gist 1994;60: 5-7.

10 Hollander A, Doekes G, Heederik DJJ. Cat and dog allergy and total IgE as risk factors of laboratory animal allergy. $\mathcal{F}$ Allergy Clin Immunol 1996;98:545-54.

11 Houba R, Heederik DJJ, Doekes G, et al. Relationship between $\alpha$-amylase allergen exposure and $\alpha$-amylase between $\alpha$-amylase allergen exposure and $\alpha$-amylase
specific sensitisation in bakery workers. Am $\mathcal{F}$ Respir Crit Care Med 1995;154:130-6.

12 Doekes G, Douwes JE, Wouters IM, et al. Enzyme mmunoassays for total and allergen-specific $\operatorname{IgE}$ in population studies. Occup Environ Med 1996;53;63-70.

13 Smid T, Heederik DJJ, Mensink G, et al. Exposure to dust, endotoxins and fungi in the animal feed industry. Am Ind Hyg Assoc F 1992;53:362-8.

14 Smid T, Heederik DJJ, Houba R, et al. Dust and endotoxin related respiratory effects in the animal feed industry. $\mathrm{Am}$ Rev Respir Dis 1992;146:1474-9.

15 Ter Kuile WM. Vergleichsmessungen mit verschiedenen Geraeten zur Bestimmung der Gesamtstaubkonzentration am Arbeitsplatz: Teil II. Staub-Reinhaltung der Luft 1984;44:211-16.

16 Douwes JE, Versloot P, Hollander A, et al. Influence of various dust sampling and extraction methods on the measure-
ment of airborne endotoxin. Appl Environ Microbiol 1995;61:1763-9. 
17 Smith PK, Krohn RI, Hermanson GT, et al. Measurement of protein using bicinchinonic acid. Anal Biochem 1985;

18 Dubois MK, Gilles A, Hamilton JK, et al. Colorimetric method for determination of sugars and related substances. Anal Chem 1956;28:350-6.

19 Doekes G, van Ieperen-van Dijk AG. Allergens of Pityrosporum ovale and Candida albicans. I. Cross-reactivity of IgE-binding components. Allergy 1993;48:394-400.

20 Houba R, van Run P, Heederik DJJ, et al. Wheat antigen exposure assessment for epidemiological studies using per- sonal dust sampling and inhibition ELISA. Clin Exp Allergy 1996;26:154-63

21 Zock J-P, Doekes G, Heederik DJJ, et al. Airborne dust antigen exposure and specific IgG response in the potato processing industry. Clin Exp Allergy 1996;26:542-8.

22 Gordon S, Tee RD, Lowson D, et al. Comparison and optimization of filter elution methods for the measurement of airborne allergen. Ann Occup Hyg 1992;36:575-87.

23 Hollander A, Gordon S, Renstroem A, et al. Comparison of methods to assess airborne rat and mouse allergen levels. I: Analysis of air samples. Allergy 1999 (in press). 